\title{
Research Sampling and Survey Design for Sea Scallops (Placopecten magellanicus) on Georges Bank
}

\author{
R. K. Mohn, G. Robert and D. L. Roddick \\ Department of Fisheries and Oceans, Biological Sciences Branch \\ P. O. Box 550, Halifax, Nova Scotia, Canada B3J 2 S7
}

\begin{abstract}
A comparison of stratification schemes developed by Canada and the United States for sea scallop surveys on Georges Bank did not provide a clear indication of a superior approach. The United States employs depth and latitude as the basis for stratification, while Canada uses strata defined from commercial catch and effort. Analysis of variance of research catch data and comparisons of the mean squares and of the reductions in variance were the criteria for comparison. Based on the standard error of abundance, at least 20 tows per stratum are advocated, but little improvement would be expected with more than 40 stations per stratum. Neither approach uses an optimal allocation of stations to strata. The highly non-proportional allocation of stations in the Canadian scheme is due to an emphasis on management and assessment of the stock on the commercially-important grounds.
\end{abstract}

\section{Introduction}

Annual research vessel surveys of Georges Bank by Canada and USA have been based on stratified sampling designs since 1977 to estimate the abundance of sea scallops (Placopecten magellanicus). Surveys of the scallop stock have been conducted since the 1950's, but they were usually made in areas which were selected as being productive fishing locations or where recruitment was reported to be high (Caddy, 1972; Posgay, 1979). The results were usually given with a resolution of $10^{\prime} \times 10^{\prime}$ (latitude $\times$ longitude) unit areas. In 1966, a Canadian survey was conducted to examine the relationships between scallop catch, fishing effort, depth and bottom type (Caddy and Chandler, MS 1969). It was concluded from the study that the best variable on which stratification could be based for research vessel surveys with respect to scallop abundance was commercial catch. Depth was found to be the next best variable. Catch-per-unit effort (CPUE) with "days fished" as a measure of fishing effort, appeared to be a poor indicator of scallop abundance.

In 1977, when stratified sampling was initiated, the Canadian stratification scheme was based on commercial fishing activity in terms of fishing effort per unit area during the preceding year (Jamieson et al., MS 1981). In 1978, commercial CPUE became the basis for stratification during the annual research vessel surveys, and CPUE levels were expressed as catch $(\mathrm{kg})$ per hour fished for the 1978 and 1979 surveys. For all subsequent annual surveys, CPUE levels $(\mathrm{kg} / \mathrm{chm})$ were expressed as catch $(\mathrm{kg})$ divided by the product of crew $(c)$, hours fished $(h)$ and meter width of dredge $(m)$. The resultant CPUE strata (1 to 4 ) were established by grouping the CPUE values (per unit area) into four categories (very low, low, medium and high). Commercial CPUE data for the preceding September-May period were used to determine the stratification pattern to be followed during the summer survey. For the USA surveys, Georges Bank was stratified into geographic zones based on four depth intervals $(15-25,26-30$, $31-40,41-60 \mathrm{fm})$. These strata are overlaid on a map which have the isobaths in meters (Fig. 1).

The object of this study was to compare the effects of the two types of stratification on the variance of the estimates of abundance and of the size (age) structure of the sea scallop population on Georges Bank.

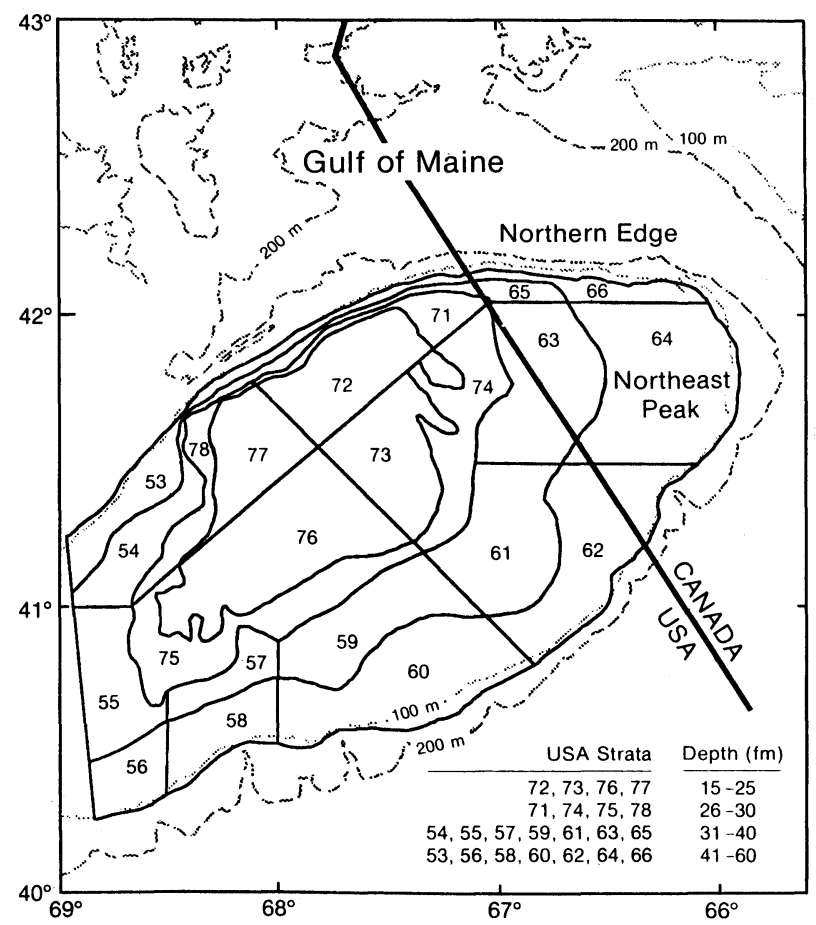

Fig. 1. The Georges Bank region with USA stratification scheme for research vessel surveys of sea scallops. 


\section{Methods}

Data from annual research vessel surveys for sea scallops on Georges Bank by Canada in 1981-84 and USA in 1981-83 (east of about $69^{\circ} \mathrm{W}$ ) form the basis for this investigation. Stratified sampling was conducted with the $2.44 \mathrm{~m}$ wide commercial scallop dredges which had a $5 \mathrm{~cm}$ ring bag for the USA surveys and a $7.5 \mathrm{~cm}$ ring bag for the Canadian surveys. Each dredge had a $3.8 \mathrm{~cm}$ mesh polyproplene liner to retain small scallops. For each tow, the position, depth, towing distance and size (shell-height) composition of the scallop catch were used in the analysis. The actual path of the vessel was used for towing distance in the Canadian data (Jamieson, 1982). The distance between endpoints of each tow was used for towing distance in the USA data. For both sets of data, the position of tow was defined as the midpoint between the start and end positions.

To assess the merits of the two stratification schemes, the Canadian data were assigned to the USA strata on the basis of position and depth (Fig. 1). Tow positions which could not be assigned to one of the defined strata were given a unique number (99). Most of these tows were made at greater depths than the $110 \mathrm{~m}$ maximum depth of the USA strata. The USA data, which were provided without specific strata numbers, were assigned to strata by the same procedure. The effect of towing distance on scallop catch (numbers) was assessed by plotting these variables. The effect of depth on catch was studied for small and large scallops with shell heights less than $90 \mathrm{~mm}$ and equal to or greater than $90 \mathrm{~mm}$ respectively. This size was chosen as the approximate size of recruitment to the commercial fishery.

Since the purpose of stratification is to reduce the variance of the survey estimates of abundance, analyses of variance were undertaken in order to compare the stratification schemes in terms of $F$ ratios. These were applied to the Canadian data as stratified by both the USA and Canadian schemes as well as to the USA data with USA stratification. Also, a test was made of differences between Canadian and USA stratification within and between mean squares for each year. The within-strata mean squares were compared by using a test of homogeneity of variances. For the betweenstrata mean squares, the estimates of variance components due to strata were compared by constructing their $95 \%$ confidence intervals (Snedecor and Cochran, 1980). The effectiveness of each stratification scheme in reducing the variance of the estimates relative to no stratification was also assessed by equations from Cochran (1977) with the finite population correction factors $\left[\left(1-n_{i} / N_{i}\right)\right.$ for equation 1 , and $(N-n) /(n-1)$ for equation 2] removed:

$$
v_{s}=\sum_{i} w_{i}^{2} \frac{s_{i}^{2}}{n_{i}}
$$

$$
V_{r}=\frac{1}{n}\left[\frac{1}{N}\left\{\sum_{i} \frac{N_{i}}{n_{i}} \sum_{j}^{n_{i}} Y_{i j}^{2}\right\}-\bar{Y}_{s}^{2}+V_{s}\right]
$$

where $V_{r}=$ variance for a simple random model; $V_{s}=$ variance for the stratified model; $\mathrm{N}=$ total number of sampling units; $n=$ number of sampling units in a sample; $N_{i}=$ total number of sampling units in stratum $i ; n_{i}=$ number of sampling units in sample from stratum $i ; W_{i}=$ stratum weight for stratum $i ; S^{2}{ }_{i}=$ variance in sample from stratum $i ; Y_{i j}=$ catch for tow $j$ from stratum $i$; and $\bar{Y}_{s}$ = estimated mean catch from stratified sampling. Gains or losses, where a gain of 1.0 is equivalent to halving the variance of the estimated mean, can thus be directly assessed by the formula

$$
\text { Gain } \left.=\left(V_{r}-V_{s}\right) / V_{s}\right)
$$

To assess the effect of sample size, the Canadian survey data for 1983 , as assigned to both the USA and Canadian stratification schemes, were subsampled and the standard error of the mean was plotted as a function of sample size. The subsampling was done with a computer program which randomly drew subsamples of size $2,4,6, \ldots, n$, where $n$ is the number of tows in a stratum. Ten replicate sets of draws were made at each subsample size.

As a check on the effect of distance between sampling stations and to obtain an indication of aggregation, all Canadian data from the Canadian stratification in 1983 and the Canadian data based on the USA stratification for each of four strata which had more than 25 tows in 1983 were sampled in two ways: pairs of randomly-selected tows were chosen in one case and the nearest geographical tows were paired in the other. The number of nearest pairs was equivalent to the number of tows in a stratum, whereas the number of randomly-chosen pairs was arbitrarily set at 120 times the number of tows in the stratum. Standard deviations of the two methods of pairing were compared.

\section{Results}

Overall shell-height frequencies of sea scallops (expressed as percentages) from the Canadian and USA surveys of Georges Bank in 1983 (Fig. 2) show essentially the same pattern. The prominant modal group of small scallops $(40-50 \mathrm{~mm})$ in the size distributions from both surveys was evident in all strata. The Canadian catch rates were slightly higher than the USA rates. This was probably due, at least in part, to the concentration of tows during the Canadian survey in commercial fishing areas of the bank. In recent years, Canadian survey coverage of the northeastern part of the bank (east of the Canada-USA boundary, Fig. 1) has been greater than USA survey coverage, and the Canadian surveys sampled deeper areas.

The effect of towing distance on catch of sea scallops (in numbers) during the 1983 surveys showed no 


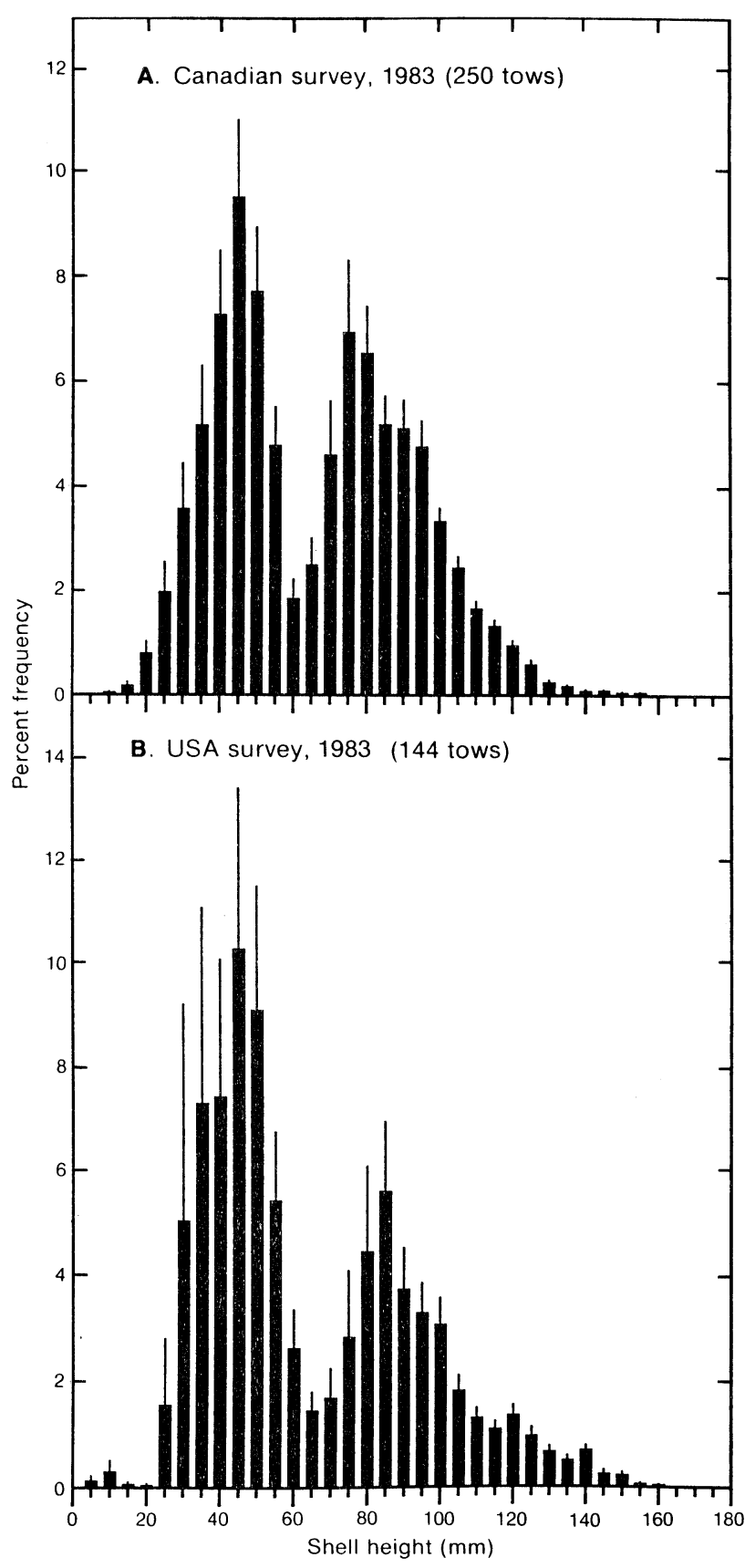

Fig. 2. Percentage shell-height frequencies of sea scallops derived from the Canadian and USA surveys of Georges Bank in 1983.

consistent or obvious trend and the correlation coefficients were very low $(0.08$ and 0.14 for the USA and Canadian data respectively). Elimination of tows with zero catch resulted in little improvement in the correlation coefficients. Nonetheless, corrections are routinely made for discrepancies in towing distance relative to the standard length of tow before data analyses are carried out.

There was no obvious trend in catches (numbers) of small prerecruited ( $<90 \mathrm{~mm}$ shell height) and larger
( $\geqslant 90 \mathrm{~mm}$ ) scallops with depth, as demonstrated by the very low correlation coefficients for the 1983 surveys (0.14 and 0.22 for the USA data, and 0.06 and 0.01 for the Canadian data). Although the Canadian survey extended to deeper areas of the slope than the USA survey, the highest abundance of both small and large scallops was found in the 70-90 $\mathrm{m}$ depth range. The correlation analysis is based on an implicit linear model, but there may be a more complex functional relationship between catch rate and depth.

Results of analyses of variance, in terms of "within" and "between" mean squares and F-ratios, indicated no significant difference $(P>0.05)$ between the Canadian and USA stratification designs (Table 1). However, the F-ratios were always higher for Canadian stratification of the Canadian data than for USA stratification of the same data. On the other hand, with respect to the variances associated with the effectiveness of random versus stratified sampling (Table 1), the stratification gain was always higher for the USA design.

From the comparison between standard deviations of data for pairs of nearest tows and random pairs of tows (Table 2), the standard deviations were consistently smaller for the nearest pairs, as expected, with one exception (Canadian strata 2).

Plots of standard error against sample size for data from selected strata (Fig. 3) indicated highly variable standard errors for sample sizes less than 20 and only slight reduction in standard errors for sample sizes greater than 40 .

\section{Discussion}

The analysis of variance of sea scallop data from Canadian and USA surveys of Georges Bank does not give a clear indication of a preferred stratification scheme. In terms of F-ratios, the Canadian scheme seems to be a better system. On the other hand, the USA scheme, when it is compared to no stratification in terms of the formulae that were used (see Methods), results in a greater reduction in variance. The lower performance of the Canadian scheme in terms of this analysis is explained by the highly non-proportional allocation of number of tows per stratum. The optimum allocation (in statistical terms) is that the strata with the largest product of area and standard deviation should be assigned the most tows. The Canadian scheme allocates a large number of tows to the portion of the bank which is important to the Canadian scallop fishery. Because this area is a small one with comparatively low variation in scallop abundance, only a few tows would be assigned to it under an optimal allocation scheme. This Canadian emphasis reflects the purpose for which the data are used, namely, the management of a resource which is exploited only over a limited area. In 
TABLE 1. Results from analysis of variance of sea scallop data from Canadian surveys in 198184 stratified by Canadian and USA designs and from USA surveys in 1981-83 based on the USA design, and a comparison of stratification effectiveness

\begin{tabular}{|c|c|c|c|c|c|c|c|c|c|}
\hline \multirow[b]{2}{*}{ Year } & \multirow[b]{2}{*}{ Data } & \multirow[b]{2}{*}{ Design } & \multirow{2}{*}{$\begin{array}{l}\text { No. of } \\
\text { tows }\end{array}$} & \multicolumn{2}{|c|}{ Mean square $(000)$} & \multirow{2}{*}{$\begin{array}{c}F \\
\text { ratio }\end{array}$} & \multicolumn{2}{|c|}{ Variances } & \multirow[b]{2}{*}{ Gain } \\
\hline & & & & Within & Between & & $V_{r}$ & $\mathrm{~V}_{\mathrm{s}}$ & \\
\hline \multirow[t]{2}{*}{1981} & Can & USA & 118 & 445.0 & $1,555.2$ & 3.5 & 3,005 & 1,874 & 0.60 \\
\hline & $"$ & Can & 118 & 442.7 & $1,898.0$ & 4.3 & - & - & - \\
\hline \multirow[t]{2}{*}{1982} & Can & USA & 182 & 20.0 & 36.0 & 1.8 & 87 & 72 & 0.21 \\
\hline & " & Can & 182 & 20.1 & 60.6 & 3.0 & 138 & 506 & -0.73 \\
\hline \multirow[t]{2}{*}{1983} & Can & USA & 250 & 17.6 & 68.3 & 3.9 & 76 & 77 & -0.02 \\
\hline & $"$ & Can & 250 & 18.6 & 85.0 & 4.6 & 94 & 137 & -0.31 \\
\hline \multirow[t]{2}{*}{1984} & Can & USA & 203 & 197.3 & $1,236.1$ & 6.3 & 798 & 361 & 1.21 \\
\hline & " & Can & 203 & 229.2 & $1,542.6$ & 6.7 & 809 & 665 & 0.22 \\
\hline 1981 & USA & USA & 51 & 1.0 & 1.2 & 1.2 & 21 & 20 & 0.07 \\
\hline 1982 & " & $"$ & 144 & 8.2 & 17.7 & 2.2 & 43 & 31 & 0.39 \\
\hline 1983 & $"$ & $"$ & 144 & 9.1 & 7.5 & 0.8 & 41 & 35 & 0.18 \\
\hline
\end{tabular}

TABLE 2. Comparison of standard deviations of random and closest pairs based on Canadian and USA stratification designs of the Canadian 1983 data. (SD = standard deviation of random pairs standard deviation.)

\begin{tabular}{ccccc}
\hline \hline Design & $\begin{array}{c}\text { Strata } \\
\text { number }\end{array}$ & $\begin{array}{c}\text { No. of } \\
\text { tows }\end{array}$ & $\begin{array}{c}\text { Standard deviations } \\
\text { pairs }\end{array}$ & $\begin{array}{c}\text { Random } \\
\text { pairs (SD) }\end{array}$ \\
\hline Can & 1 & 75 & 56 & $69(4.0)$ \\
& 2 & 17 & 183 & $156(20.8)$ \\
& 3 & 58 & 36 & $51(7.2)$ \\
& 4 & 100 & 65 & $76(5.3)$ \\
USA & 63 & 33 & 12 & $31(4.0)$ \\
& 64 & 111 & 45 & $68(4.0)$ \\
& 66 & 25 & 102 & $130(13.8)$ \\
& 99 & 29 & 117 & $131(16.4)$ \\
\hline
\end{tabular}

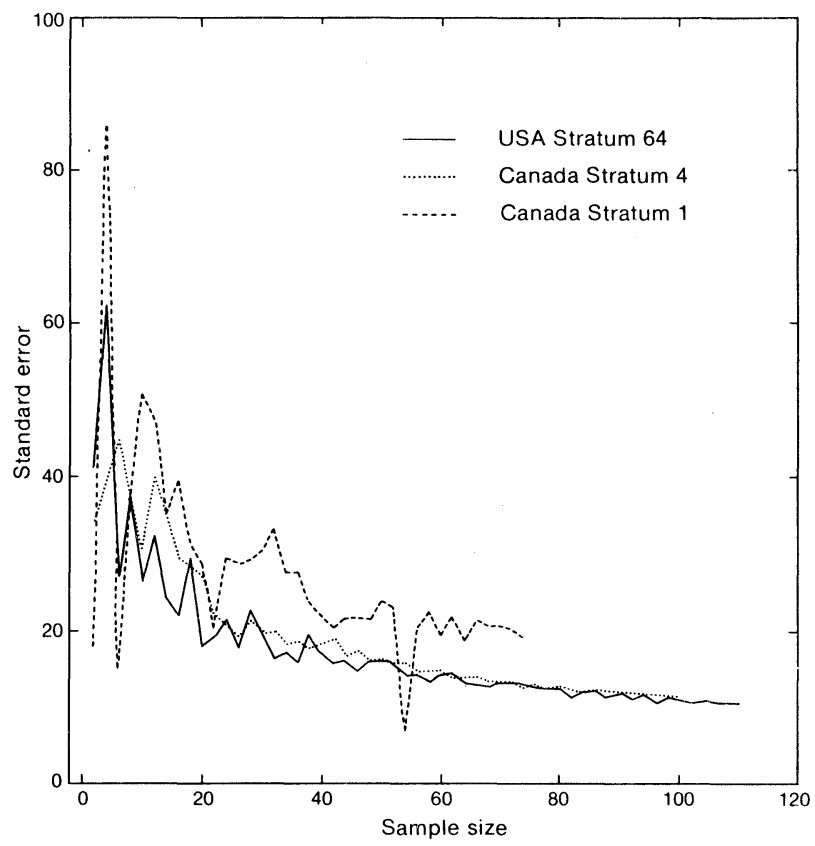

Fig. 3. Relationship between standard error of mean catch and sample size (Number of tows) for selected strata from the Canadian and USA surveys of Georges Bank in 1983. other words, the emphasis is on estimating fishable biomass rather than total biomass.

Results of the analysis of random versus nearest pairs of tows indicated that the scale of aggregation of sea scallops is very small. In terms of abundance, data from nearest tows varied almost as much as data from randomly-chosen pairs of tows within the stratum. This obvservation is consistent with that of Bourne et al. (MS 1964), who noted that catches from simultaneous tows on the left and right sides of the vessel sometimes had greater variance than separate tows. This indistinct pattern of aggregation is also implied by the poor relationship between towing distance and scallop catch. It is unlikely that stratification could be made fine enough to take scallop aggregation into account and still fulfill the requirement of sampling the fishable biomass over areas of commercial exploitation. The trends in Fig. 3 indicate that at least 20 tows per stratum are needed to stabilize the estimate of the mean, and that little benefit (in terms of variance) would be expected with more than 40 tows per stratum.

Stratification of Canadian research vessel surveys by using pre-survey commercial data has undergone several changes for this scallop resource. The first scheme was based on commercial fishing effort with a resolution of $10^{\prime} \times 10^{\prime}$ unit areas. In the late 1960's, a study by Caddy and Chandler (MS 1969) indicated that catch was a better index of stock abundance. In the late 1970's, Jamieson et al. (MS 1981) advocated a stratification scheme which is based each year on commercial CPUE data during the preceding several months, and that scheme is still used for the Canadian scallop surveys. Preliminary analysis of Canadian 1981 data with "days fished" as a measure of effort resulted in a poor relationship between CPUE and stock abundance on a $10^{\prime} \times 10^{\prime}$ unit-area basis for the portion of Georges Bank east of the Canadian-USA boundary. However, the catch and fishing effort in these unit areas had a very high correlation $(r>0.99)$. These relationships are cur- 
rently being investigated with the use of a more precise database. The Canadian estimates of biomass are not derived from either the simple random or the randomstratified methods which were discussed above. Instead, a post-stratification scheme for each yearclass of scallops has been developed and is currently being reviewed.

\section{Acknowledgements}

We thank Fred Serchuck of the U.S. National Marine Fisheries Service, Northeast Fisheries Center, Woods Hole, Massachusetts, for kindly providing the sea scallop data from the USA surveys. Among personnel of the Biological Sciences Branch of the Canadian Department of Fisheries and Oceans, Halifax, Nova Scotia, we thank Raj Misra for his statistical advice and Marianne Etter for help in preparation of the manuscript.

\section{References}

BOURNE, N., E. CADIMA, and J. E. PALOHEIMO. MS 1964.
Studies on Georges Bank sea scallop abundance and distribution. ICNAF Meet. Doc., No. 65, Serial No. 1361, $4 \mathrm{p}$.

CADDY, J. F. 1972. Size selectivity of the Georges Bank offshore dredge and mortality estimate for scallops from the northern edge of Georges Bank in the period June 1970 to 1971. ICNAF Redbook, 1972(III): 79-85.

CADDY, J. F., and R. A. CHANDLER. MS 1969. Georges Bank scallop survey August 1966: a preliminary study of the relationship between research vesel catch, depth, and commercial effort. Fish. Res. Board Can. MS Rep., No. 1054, $15 \mathrm{p}$.

COCHRAN, W. G. 1977. Sampling techniques (3rd edition). John Wiley and Sons Inc., New York, N. Y., 428 p.

JAMIESON, G. S. 1982. A system for the precise determination of tow distance and tow path in offshore resource surveys. Can. Tech. Rep. Fish. Aquat. Sci., 1035: 34 p.

JAMIESON, G. S., M. J. LUNDY, G. L. KERR, and N. B. WITHERSPOON. MS 1981. Fishery characteristics and stock status of Georges Bank scallops. Can. Atl. Fish. Sci. Advis. Committee Res. Doc., No. 70, 35 p.

POSGAY, J. A. 1979. Population assessment of the Georges Bank sea scallop stocks. ICES Rapp. Proc.-Verb., 175: 109-113.

SNEDECOR, G. W., and W. G. COCHRAN. 1980. Statistical methods. lowa State Univ. Press, Ames, lowa, 507 p. 
